\title{
Comparative Study of Some Lipid Contents of Selected Fishes in Bayelsa State, Nigeria.
}

\author{
O.O. Ezomoh ${ }^{1}$ and C. H. Madukosiri ${ }^{2} *$ \\ ${ }^{1,2}$ Department of Biochemistry, College of Health Sciences, Niger Delta University, Nigeria. \\ (*correspondent Author's email: gginl@yahoo.com
}

\begin{abstract}
The present study compared the fatty acids, cholesterol, low density lipoprotein (LDL), and high density lipoprotein (HDL) of four commercially important fresh-water fish species, Clarias gariepinus $(C G)$, Oreochromis niloticus (ON), Synodontis budgetti (SB), and Mormyrops deliciosus MD), using Gas Chromatographic and High Performance Lipid Chromatographic methods. Results showed that the percent polyunsaturated fatty acids (PUFAs) determined from CG were, 35.709, 14.310, 45.845 and 32.345, from Amassoma, Swali, Tombia (in Bayelsa State, South-South of Nigeria) and Lagos rivers respectively. The prominent omega-3 fatty acid determined were eicosapentaenoic acid (EPA) and docosahexaenoic acid (DHA); while the major omega-6 fatty acid was eicosatetraenoic acid (AA). Cholesterol content of fishes from the study rivers ranged from 5.080 to $5.570(\mathrm{mg} / 100 \mathrm{~g} \mathrm{DW})$ and was more or less significantly lower than that from Lagos river (in a populous city in the South-west of Nigeria), $(p<0.05)$. Cholesterol, HDL and LDL content in the four fish species were according to the decreasing order $C G>O N>S R . M D$. For the HDL content of fish, higher value was obtained from Amassoma than those of Swali and Tombia rivers but (with the exception of that of O. niloticus in Amassoma) were all found to be significantly lower than that of Lagos, $(p<0.05)$. Fishes from Amassoma and Lagos rivers were prominent in n-3 PUFA particularly DHA and EPA; while those from SR showed the lowest levels. This information should find application not only for institutional feed and culture development in fisheries but for individual / institutional nutrition guide and dietary recommendation. Keywords: Fish, lipids, fatty acids, cholesterol.
\end{abstract}

\section{Introduction}

Water bodies could harbour varieties of animal species that serve as important food nutrient sources to man. Fish is one of the important sources of the macro-nutrients - oils / lipids rich in essential fatty acids [1]. Fatty acids can exist as nonesterified free fatty acids (minor portion) in circulating plasma lipids or tissue stores which are sensitive to physiological energy demands [2]. However esterified fatty acids are integral part of most lipids. Natural fatty acids have 14 to 22 carbon length (including the carboxylic acid carbon), and only those with even numbers occur naturally in mammals. They are grouped according to the absence or presence of double bonds in their chains - the saturated (SFA), monounsaturated (MUFA) and the polyunsaturated (PUFA) fatty acids [2].

Fish lipids are derived from the tissues of oily fish (particularly the fish muscle) and contain essential fatty acids such as the omega-3 (w-3or n-3) fatty acids - $\alpha$-linolenic acid (ALA) or octadecatrienoic acid obtainable from plant oil, eicosapentaenoic acid (EPA) and decosahexaenoic acid (DHA) known to be beneficial for health [2]. Other essential fatty acid components are the members of omega-6 (w-6 or n-6) fatty acids, linoleic acid $(9,12$,-octadecadienoic acid) and arachidonic acid (5,8,11,14-eicosatetraenoic acid). These long chain n-3 and n-6 PUFAs (polyunsaturated fatty acids) are termed essential as they cannot be synthesized by man and so must be supplied by the diet. When consumed, they regulate prostaglandin synthesis and hence induce wound healing [3]. Such essential fatty acids function as anti-inflammatory agents and have been found beneficial in the prevention and management of cardiovascular diseases [4, 5]. They had also been shown to have positive effects, not only in the treatment of cardiovascular diseases but of certain cancers [6].

Cholesterol is a waxy fat-like substance that is present in all animals but not in plant. It is not soluble in blood and so has to be carried in the bloodstream by molecules called lipoproteins [2]. Lipoproteins are named based on their density. The high density lipoprotein (HDL) is 'good' and transports cholesterol to the liver for further processing. Low density lipoprotein is 'bad' fat and when oxidized gets deposited in the walls of arteries contributing to arteriosclerosis [7]. The former is so named because it is known to contain less cholesterol and more phospholipids and apoproteins than the later. HDL is present in higher amount in fish lipids, whereas the LDL is more abundant in other animal fats and contains more of the saturated fatty acids (SFA). It had been established that the total cholesterol and LDL cholesterol are the major dietary contributors to artherosclerosis and the consequent coronary heart diseases (CHD) [2]. Contrarily, HDL cholesterol concentration showed protection against CHD [2]. However cholesterol is an important constituent of membranes and a precursor 
molecule for the synthesis of vitamin D and the steroid hormones including adrenal glands cortisol and aldosterone, the sex hormones, estrogens, testosterone and their derivatives. Although cholesterol is mostly supplied by consumption of animal rich foods, it is also endogenously synthesized, with about $90 \%$ of its synthesis occurring in the liver and intestine. In the liver it is converted to bile acids and bile salts necessary for solubilization of fats into mixed micells in the digestive tract, thereby aiding intestinal digestion and absorption of fat molecules as well as the fat soluble vitamins A, D, E, and K. Fishes categorized as High fat fishes can raise 'good' cholesterol (HDL) levels [9]. Therefore intake of different classes of lipids must be balanced in order to maintain good health.

Some important fish species accounting for Bayelsa's fishery are those belonging to Animalia chordate of the class Actnopterygii and include Oreochromus niloticus of the family of Cichlidae, (also known as Nile tilapia); Clarias gariepinus of Claridae (African sharp tooth cat fish); Synodontis budgetti, Mochokidae (upsidedown catfish) which is a component of local commercial fishes; and Mormyrops deliciosus (Conish jack) demersal species of tropical freshwater habitats [9].Presently there has been a move for the expansion of aquaculture in Nigeria especially the culture of African catfish, $C$. gariepinus due to its characteristics such as tolerance to a wide range of temperatures, fast growth, adaptation to disease environment as well as to low oxygen and high salinity levels [9]. This move is informed by the relative increase in the development of cardiovascular related diseases coupled with the deficit of PUFA in human diet [9]. The increased awareness of health benefits of eating fish was reported to have raised the estimated fish demand in Nigeria to 1.80 million tons [10]. That estimation was then based on a population of 120 million people and per capita global consumption of $15 \mathrm{~kg}$, the later which was well above Nigerians' average [11]. The current estimation of fish consumption in Nigeria may not have changed much as it is based on a population of 170million with an annual consumption of 7.5 to $9 \mathrm{Kg}$ per person [11].

The successful implementation of aquacultures which shall adequately augment the demand for fish by any country with the aim of meeting the health /nutritional needs of its people require adequate base-line information on the pre-existing nutritional indicators / components in the fishes being targeted. Such studies no doubt provide the necessary information required for feed modification (for example where it is required to increase n-3 / n-6 PUFA ) of cultures that form part of our diet - an important approach for increasing the consumption of the targeted nutrient(s) in our foods. The present study therefore presents and compares the fatty acid, cholesterol, HDL and LDL components of commonly consumed fishes in Bayelsa State. These data would find application not just for industrial feed and culture development in fisheries but for individual nutritional information as well as dietary recommendations / management by Clinicians and Dieticians.

\subsection{Sample Preparation}

\section{Methods}

Freshly captured fishes Clarias gariepinus, Synodontis Budgetti, Oreochromis niloticus and Mormyrops deliciosus, obtained from Bayelsa water bodies and Ikorodu river in Lagos state, were sorted and identified by an expert in the Department of fisheries, Niger Delta University. Fish samples were obtained between the months of April and May 2015. The fishes were weighed, decapitated, eviscerated, cleaned and held in polyethylene packing (in $\mathrm{N}_{2}$ atmosphere) prior to freezing at $-22^{0} \mathrm{C}$. At the beginning of each analysis the samples were allowed to equilibrate to room temperature, triturated and homogenized before extraction.

\subsubsection{Lipid Extraction}

Soxhlet extraction of fish lipids was carried out according to the method of AOAC [12]. In this method $250 \mathrm{ml}$ capacity extracting flask was dried in the oven at $60^{\circ} \mathrm{C}$, then transferred to the desiccator to cool to the laboratory temperature before the weight of the flask was measured. About $2.5 \mathrm{~g}$ of the sample was weighed into the labeled porous thimble, while $200 \mathrm{ml}$ of the petroleum ether was measured into the dried $250 \mathrm{ml}$ capacity flask. The covered porous thimble with the sample was placed in the condenser of the apparatus and extracted for five (5) hours. At the end of extraction the flask with the oil was oven dried at $60^{\circ} \mathrm{C}$ for one (1) hour to get rid of the moisture and then cooled in a desiccator before weighing. The results (means \pm standard deviation) were calculated as the weight percentage.

\subsubsection{Fatty Acid Analysis}

The fatty acids were analyzed as their methyl esters with a gas chromatography HP 6890 Powered with HP ChemStation Rev. A 09.01 [1206] Software.Upto 50mg of the extracted fat content of the sample was saponified for five (5) minutes at $90^{\circ} \mathrm{C}$ with $3.4 \mathrm{ml}$ of the $0.5 \mathrm{M} \mathrm{KOH}$ in dry methanol. The mixture was neutralized using $0.7 \mathrm{HCL}$, after which $3 \mathrm{ml}$ of $14 \%$ boron triflouride in methanol was added and heated for 5 minutes at $90^{\circ} \mathrm{C}$ to achieve complete methylation process. The Fatty Acid Methyl Esters were thrice extracted from the mixture with redistilled $\mathrm{n}$-hexane. The content was concentrated to $1 \mathrm{ml}$ for gas chromatographic analysis. Separation was carried out in a capillary column $(30 \mathrm{~m} \times 0.25 \mathrm{~mm}$ id $\mathrm{x} 0.25 \mu \mathrm{m}$ of DB wax $)$. The oven 
initial temperature was $60^{\circ} \mathrm{C}$, first ramping was raised to $12^{\circ} \mathrm{C} / \mathrm{min}$ for $20 \mathrm{~min}$, maintained for 2 minute, and second ramping at $15^{\circ} \mathrm{C} / \mathrm{min}$ for $3 \mathrm{~min}$, maintained for 8 minute. In-lel and detector temperatures were $250^{\circ} \mathrm{C}$ and $320^{\circ} \mathrm{C}$ respectively. Hydrogen pressure and compressed air were 22 and 35 (psi), in that order. The total running time was 10 minutes. Nitrogen was the carrier gas, while the injection volume was $1 \mu$ l. FAME identification was made by comparison with the retention times of the known standards, 37 component FAME mixture (Supelco).

\subsubsection{Determination of low density lipoprotein and high density lipoprotein-Cholesterol}

The phytosterol extraction and analysis were carried out by the modified method of AOAC 994.10 and AOAC 970.51 Official methods [12].About $0.5 \mathrm{~g}$ of the extract from the sample was added to the screw-capped test tube and saponified at $95^{\circ} \mathrm{C}$ for 30 minutes by using $3 \mathrm{ml}$ of $10 \% \mathrm{KOH}$ in ethanol to which $0.20 \mathrm{ml}$ of benzene had been added to ensure miscibility. Into the mixture were added $3 \mathrm{ml}$ of de-ionised water and $2 \mathrm{ml}$ of hexane to extract the non-saponifiable materials. Three extractions, lasting for 1 hour, 30 minutes and 39minutes each with $2 \mathrm{ml}$ of hexane were carried out in order to achieve complete extraction of the sterols. The extract was concentrated to $2 \mathrm{ml}$ in Agilent vial for gas chromatographic analysis.

\section{Results}

The mean $( \pm \mathrm{SD})$ values of total fat determined from the four commercial fish species [C. gariepinus (CG), O. niloticus (ON or Tilapia), M. deliciosus (MD), and S. budgetti (SB)] in the three different rivers Amassoma (AR), Swali (SR), Tombia (TR) in Bayelsa State and Ikorodu in Lagos (LR) were between $0.001 \pm$ 0.001 and $26.996 \pm 0.460,0.001 \pm 0.001$ and $24.459 \pm 0.091,0.001 \pm 0.001$ and $26.127 \pm 0.081$, and $0.001 \pm$ 0.001 and $26.212 \pm 0.118(\%)$, respectively. The profiles and percent composition of 30 different fatty acids with various chain lengths and saturation levels are presented (Tables 1-4). The principal saturated fatty acids (SFAs) identified were C16:0, C18:0, C14:0, C24:0 and C22:0 (accounting for 4.967 - 43.343mg/100g); the monounsaturated fatty acids (MUFA) were C18:1(trans-6; 9; and cis-6), C16:1(cis-9) and C14:1(cis-9), C20:1; C22:1; C24:1, (6.794-45.848mg/100g); while the dominant polyunsaturated fatty acids (PUFA) were C22:6( cis-4,7,10,13,16,19), C20:5 (cis-5,8,11,14,17) and C20:4( cis-4,8,11,14), (6.794 - 45.848mg/100g). The percentage PUFAs (in CG) from the four study locations were according to the deceasing order TR $(45.845)>$ AR (35.708) > LR (32.345) > SR (14.310). The n-6/n3 ratio for LR, AR, SR and TR locations were from 0.335 $-0.427,0.259-0.431,0.043-1.088$ and $0.444-0.837$ respectively (Table 5). Among the fish species SB (0.259) in Amassoma, MD (0.043), and SB (0.053) in Swali river presented the lowest values. The PUFA/ SFA ratios obtained ranged from 0.489 (SB in Amassoma) to 1.838 (MB in Tombia). The range of cholesterol values in the four fishes from LR was higher when compared to those obtained from fishes in the other rivers; and they follow the decreasing order: $\operatorname{LR}(5.523-5.686)>\mathrm{AR}(5.231-5.518)>\mathrm{SR}(5.130-5.508)>\mathrm{TR}(5.08-5.202)$ (Table 6). Cholesterol levels in ON and SB (Lagos river) were significantly different from those obtained from counterpart locations $(\mathrm{p}<0.05)$. The values of HDL and LDL determined were seen to follow the same decreasing order as those of cholesterol levels, (Table 6).

\section{Discussion}

The fish species studied belong to High fat fish (> 8\%) category, going by the classification of Ackman .[13]. The lower side of the lipid range $(0.00$ to $27.456 \%)$ is in line with some literature report [14, 15]. Apart from the issues of seasonal variations between dry and rainy seasons which are known to affect fat content of fishes, spawning activities can use-up the fat reserves and give very low fat levels [16, 17]. Other causes of variation in fat content are (as already mentioned) attributed to geographical differences and particularly the feed-type $[18,19,20]$. Cholesterol levels determined were consistent with the report of Mendez et al [21] but lower than those of Jeyasanta and Patterson, [22] and Javitt, [23]. Of the total cholesterol determined, HDL values were higher than their corresponding LDL levels and of which was also in consonant with literature report [24]. However it was observed that the presence of trans fatty acids could have a lowering effect on the body's HDL cholesterol - an effect which underscores the need to keep the level of the former low (not to rise above $\%$ of total energy intake), if the HDL level should be maintained [25].

The levels of PUFA determined from fishes in LR, AR \& TR were similar; but were all higher than that from SR'. The species $C$. gariepinus was the major contributor of PUFA in each study location, thereby confirming the fact that species differences is one of the major factors in nutrient accumulation [22, 26]. The present study therefore support the production of aquaculture of $\mathrm{C} \mathrm{G}$. Prominent PUFAs in fishes in LR were C20:4, C20:5 and C22:6; while those of AR included, together with the above acids, the C18:2. Fishes from SR and TR featured mostly the C18:3, C20:3; and C18:2, C20:3, C20:4, C22:2, C20:5, C:22:6 acids respectively, and agreed with literature reports, $[1,27]$.

Still among the PUFAs, C18:2 (linoleic) was prominent in fishes from TR, AR \& LR. The C18:3(linolenic) was more prominent in SR fishes. Both acids are vital for growth and development and therefore must be provided in the diet since the body cannot synthesize them. With them available, the body can 
synthesize arachidonic and other eicosanoids. Arachidonic acid is the precursor molecule for prostaglandin synthesis and myelination of the central nervous system. Contrary to the observation of Ugoala et al, [28], our determinations show that freshwater fishes can also serve as good sources of omega-3 essential fatty acids. Chief among the n-3 sources are fishes from LR, AR and TR. The work of Justi et al [1] showed that fatty acid composition of freshwater fish was characterized by linoleic (C18:2n-6), a-linolenic (C18:3n-3) and EPA (C20:5n-3). The present determination showed that the n-6 PUFA compositions were mainly linoleic (C18:2) and arachidonic (AA, C20:4n-6) acids; while the n-3 PUFAs were found mostly to be C20:5 (cis-5,8,11,14,17) (or EPA) and C22:6n-6 (or DHA) and on the average higher than some reported in literature [1,29]. Among the Study Rivers, fishes from LR and AR showed higher values of EPA and DHA than those of SR and TR. The n-6 / n-3 ratios were lower than unitary and therefore below the maximum recommendation of 4.0 in the above cited literature. Judging by recent literature publications that ratio is in consonant with good health [25]. According to those reports, high $\mathrm{n}-6 / \mathrm{n}-3$ fatty acid ratio is associated with an increased risk of colorectal, prostate and breast cancers. Since a risk associated with $\mathrm{n}-6$ has not been demonstrated, it was concluded that a low n-3 PUFA intake is responsible for that observation. Thus an absolute amount of EPA and DHA intake (of about $500 \mathrm{mg} /$ day) was recommended rather than the ratio.

The PUFA / SFA ratios obtained (ranging from 0.489 - 1.838) were found to be higher than the minimum (0.45) recommendation [25], showing that the fishes contained reasonable PUFA levels which was deemed beneficial to health. However high content of PUFA means higher degree of unsaturation of fatty acids and increased susceptibility to lipid oxidation. This means the fishes might be less suitability for local processing methods such as smoking, frying, and sun-drying when compared to those with lower PUFA levels. Therefore high fat fishes (as in the present case) require longer periods of processing under controlled temperature as used in cold technique $\left(45-60^{\circ} \mathrm{C}\right)$. Another adverse effect of high PUFA level could be the need for use of high amount of hydrogen during hydrogenation processes. Apart from the afore mentioned constraints, the present fish species (especially CG) can serve as good sources of PUFAs which are nutritionally beneficial to health, and organoleptically acceptable since they are linked with product flavor enhancement [28]. Although these fishes are good sources of EFA, at the present level of per capita fish consumption in Nigeria they are unlikely to meet the recommended daily intake of EFA (0.5 - 1g/day) given in literatures [25, 31].

\section{Conclusion}

The fishes studied belong to High Fat Fish category. The fat accumulation was related to species type, nature of feed and hence geographical location. Cholesterol was the prominent fat followed by HDL and LDL in that order. Lower levels were determined from the study areas in Bayelsa State than in Ikorodu (Lagos State). The fish, C. gariepinus seemed more nutritionally promising in terms of essential fatty acid (EFA) content. It is therefore recommended for culture production as it contained reasonable levels of EFA and showed higher values of total PUFA when compared to the other fish types in the habitats studied. The PUFA / SFA ratios determined were higher than the minimum literature recommendation. All fish types in the studied freshwater bodies contained low levels of linoleic acid but high values of linolenic acid. On the other hand, freshwater rivers in Lagos (Ikorodu) and Amassoma presented the best sources for \% composition of n-3 (EPA and DHA) and $n-6$ of total PUFAs; while those of Swali and Tombia had the least levels. The present study has therefore provided good sources of fish oils rich in essential polyunsaturated fatty acids particularly EPA, DHA and the n6 PUFA - eicosatetraenoic acid (arachidonic acid). Increased fish production in Amassoma and Lagos areas in Nigeria is recommended so as to provide more EFAs needed for good health. Studies of this type form an important base-line study for further development and processing in fish cultures with the goal of production and supply of the essential nutritional factors that should meet the health needs of humans. They also provide nutritional information for individual's choices and institutional dietary recommendation.

Table 1. Fatty acids profile of freshwater fish species in Lagos River

\begin{tabular}{|l|l|l|l|l|}
\hline Fatty acids, SFA $(\%)$ & Clarias gariepinus & Tilapia & Mormyrops deliciosus & Synodontis budgetti \\
\hline C12:0 & $0.006 \pm 0.008$ & $0.008 \pm 0.009$ & $0.006 \pm 0.006$ & $0.009 \pm 0.005$ \\
\hline C14:0 & $2.198 \pm 0.068$ & $1.820 \pm 0.082$ & $1.925 \pm 0.078$ & $1.769 \pm 0.128$ \\
\hline C16:0 & $26.212 \pm 0.118$ & $20.820 \pm 1.313$ & $17.384 \pm 0.765$ & $23.350 \pm 0.829$ \\
\hline C18:0 & $7.447 \pm 0.010$ & $6.824 \pm 0.066$ & $5.572 \pm 0.172$ & $4.195 \pm 0.098$ \\
\hline C20:0 & $0.004 \pm 0.006$ & $0.008 \pm 0.008$ & $0.004 \pm 0.001$ & $0.001 \pm 0.001$ \\
\hline C22:0 & $0.005 \pm 0.006$ & $0.005 \pm 0.004$ & $0.003 \pm 0.001$ & $0.002 \pm 0.001$ \\
\hline C24:0 & $0.001 \pm 0.001$ & $0.003 \pm 0.001$ & $0.002 \pm 0.001$ & $0.002 \pm 0.001$ \\
\hline$\sum X$ & $\mathbf{3 5 . 8 7 3}$ & $\mathbf{2 9 . 4 8 8}$ & $\mathbf{2 4 . 8 9 6}$ & $\mathbf{2 9 . 3 2 8}$ \\
Mean \pm SD & $\mathbf{5 . 1 2 5} \pm 9.691$ & $\mathbf{4 . 2 1 3} \pm 7.367$ & $\mathbf{3 . 5 5 7} \pm 6.434$ & $\mathbf{4 . 1 9 0} \pm 8.593$ \\
\hline
\end{tabular}

\begin{tabular}{|l|l|l|l|l|}
\hline Fatty acids, MUFA (\%) & Clarias gariepinus & Tilapia & Mormyrops deliciosus & Synodontis budgetti \\
\hline C14:1 (cis-9) & $0.001 \pm 0.001$ & $0.002 \pm 0.001$ & $0.001 \pm 0.001$ & ND \\
\hline C16:1 (cis-9) & $4.589 \pm 0.142$ & $3.102 \pm 0.610$ & $2.834 \pm 0.071$ & $2.968 \pm 0.210$ \\
\hline
\end{tabular}


Comparative Study of Some Lipid Contents of Selected Fishes In Bayelsa State, Nigeria.

\begin{tabular}{|l|l|l|l|l|}
\hline C18:1 (trans-6) & $0.002 \pm 0.002$ & $0.003 \pm 0.001$ & $0.003 \pm 0.003$ & ND \\
\hline C18:1 (cis-6) & $12.374 \pm 0.119$ & $10.006 \pm 0.401$ & $7.731 \pm 0.883$ & $9.792 \pm 1.012$ \\
\hline C18:1 (trans-9) & $3.062 \pm 4.327$ & $2.905 \pm 4.107$ & $0.005 \pm 0.002$ & ND \\
\hline C18:1 (cis-9) & $8.859 \pm 0.375$ & $6.720 \pm 1.131$ & $6.231 \pm 0.966$ & $5.803 \pm 1.016$ \\
\hline C18:1 (trans-11) & $0.002 \pm 0.002$ & $0.007 \pm 0.001$ & ND & ND \\
\hline C20:1 (cis-11) & $2.268 \pm 0.073$ & $1.962 \pm 0.119$ & $1.737 \pm 0.061$ & $1.641 \pm 0.082$ \\
\hline C22:1 (cis-13) & $0.680 \pm 0.086$ & $0.457 \pm 0.100$ & $0.380 \pm 0.063$ & $0.469 \pm 0.055$ \\
\hline C24:1 (cis-15) & $0.001 \pm 0.001$ & $0.002 \pm 0.001$ & $0.002 \pm 0.001$ & ND \\
\hline$\sum X$ & $\mathbf{3 1 . 8 3 8}$ & $\mathbf{2 5 . 1 6 6}$ & $\mathbf{1 8 . 9 2 4}$ & $\mathbf{2 0 . 6 7 3}$ \\
Mean \pm SD & $\mathbf{3 . 1 8 4} \pm 4.298$ & $\mathbf{2 . 5 1 7} \pm 3.400$ & $\mathbf{2 . 1 0 3} \pm 2.958$ & $\mathbf{4 . 1 3 5} \pm 3.735$ \\
\hline
\end{tabular}

\begin{tabular}{|l|l|l|l|l|}
\hline Fatty acids, PUFA $(\%)$ & Clarias gariepinus & Tilapia & Mormyrops deliciosus & Synodontis budgetti \\
\hline C18:2 (cis-9,13) & $2.502 \pm 0.010$ & $1.751 \pm 0.134$ & $1.995 \pm 0.168$ & $1.769 \pm 0.073$ \\
\hline C18:2 (trans-9,12) & $0.002 \pm 0.002$ & ND & $0.002 \pm 0.002$ & ND \\
\hline C18:3 (cis- 6,9,12) & $0.010 \pm 0.007$ & $0.004 \pm 0.006$ & $0.005 \pm 0.007$ & $0.001 \pm 0.001$ \\
\hline C18:3 (cis 9,12,15) & $0.004 \pm 0.006$ & $0.004 \pm 0.005$ & $0.005 \pm 0.007$ & $0.038 \pm 0.051$ \\
\hline C20:2 (cis-11,14) & $0.001 \pm 0.001$ & $0.002 \pm 0.001$ & $0.001 \pm 0.001$ & $0.001 \pm 0.001$ \\
\hline C20:3 (cis-8,11,14) & $0.026 \pm 0.036$ & $0.025 \pm 0.026$ & $0.003 \pm 0.001$ & $0.014 \pm 0.019$ \\
\hline C20:3 (cis-11,14,17) & $0.003 \pm 0.004$ & $0.002 \pm 0.003$ & $0.003 \pm 0.001$ & $0.003 \pm 0.002$ \\
\hline C20:4 (cis-5,8,11,14) & $9.652 \pm 0.154$ & $7.923 \pm 0.784$ & $6.884 \pm 0.780$ & $5.679 \pm 0.691$ \\
\hline C22:2 (cis-13,16) & $0.028 \pm 0.039$ & $0.025 \pm 0.036$ & $0.019 \pm 0.0219$ & $0.004 \pm 0.002$ \\
\hline C20:5 (cis-5,8,11,14,17) & $5.974 \pm 0.099$ & $5.174 \pm 0.432$ & $4.233 \pm 0.263$ & $4.411 \pm 0.449$ \\
\hline C22:6 (cis-4,7,10,13,16,19) & $16.645 \pm 0.099$ & $14.511 \pm 0.788$ & $13.531 \pm 0.219$ & $12.504 \pm 0.572$ \\
\hline$\sum x$ & $\mathbf{3 2 . 3 4 5}$ & $\mathbf{2 7 . 6 7 0}$ & $\mathbf{2 4 . 6 8 6}$ & $\mathbf{2 2 . 6 5 5}$ \\
Mean \pm SD & $\mathbf{3 . 2 3 5} \pm 5.786$ & $\mathbf{3 . 0 7 4} \pm 5.185$ & $\mathbf{2 . 4 6 9} \pm 4.564$ & $\mathbf{2 . 5 1 7} \pm \mathbf{4 . 3 4 5}$ \\
\hline
\end{tabular}

SFA, MUF, PUFA, saturated fatty acid, monounsaturated fatty acid and polyunsaturated fatty acid respectively

Table 2. Fatty acids profile of freshwater fish species Amassoma River

\begin{tabular}{|l|l|l|l|l|}
\hline Fatty acids, SFA $(\%)$ & Clarias gariepinus & Tilapia & Mormyrops deliciosus & Synodontis budgetti \\
\hline C12:0 & $0.006 \pm 0.006$ & $0.004 \pm 0.005$ & ND & ND \\
\hline C14:0 & $2.229 \pm 0.460$ & $1.820 \pm 0.086$ & $1.691 \pm 0.029$ & $1.591 \pm 0.049$ \\
\hline C16:0 & $26.996 \pm 0.460$ & $24.320 \pm 0.292$ & $22.414 \pm 0.216$ & $20.234 \pm 0.078$ \\
\hline C18:0 & $8.210 \pm 0.289$ & $6.301 \pm 0.037$ & $5.344 \pm 0.066$ & $3.328 \pm 0.033$ \\
\hline C20:0 & $0.004 \pm 0.005$ & ND & ND & ND \\
\hline C22:0 & $0.004 \pm 0.005$ & $0.001 \pm 0.008$ & ND & ND \\
\hline C24:0 & $2.432 \pm 1.719$ & $1.034 \pm 1.302$ & $0.401 \pm 0.565$ & $0.760 \pm 0.549$ \\
\hline$\sum X$ & $\mathbf{3 9 . 8 8}$ & $\mathbf{3 3 . 4 8}$ & $\mathbf{2 9 . 8 5}$ & $\mathbf{2 5 . 9 1}$ \\
Mean \pm SD & $\mathbf{5 . 6 9 7} \pm 9.831$ & $\mathbf{4 . 7 8 4} \pm 8.90$ & $\mathbf{7 . 4 6 2} \pm 10.185$ & $\mathbf{6 . 4 7 8} \pm 9.233$ \\
\hline
\end{tabular}

\begin{tabular}{|l|l|l|l|l|}
\hline Fatty acids, MUFA $(\%)$ & Clarias gariepinus & Tilapia & Mormyrops deliciosus & Synodontis budgetti \\
\hline C14:1 (cis-9) & $0.001 \pm 0.001$ & $0.001 \pm 0.001$ & ND & ND \\
\hline C16:1 (cis-9) & $5.428 \pm 0.086$ & $4.289 \pm 0.164$ & $3.628 \pm 0.087$ & $2.792 \pm .0763$ \\
\hline C18: 1 (trans-6) & $0.001 \pm 0.001$ & $0.002 \pm 0.004$ & ND & ND \\
\hline C18:1 (cis-6) & $13.746 \pm 0.090$ & $11.482 \pm 0.121$ & $9.383 \pm 0.168$ & $7.287 \pm 0.118$ \\
\hline C18:1 (trans-9) & $0.684 \pm 0.483$ & $0.814 \pm 0.085$ & $0.552 \pm 0.043$ & $0.364 \pm 0.061$ \\
\hline C18: (cis-9) & $7.450 \pm 0.257$ & $6.298 \pm 0.288$ & $3.221 \pm 0.180$ & $2.262 \pm 0.232$ \\
\hline C18:1 (trans-11) & $0.003 \pm 0.005$ & ND & ND & ND \\
\hline C20:1 (cis-11) & $2.667 \pm 0.067$ & $1.194 \pm 0.146$ & $0.727 \pm 0.179$ & $0.418 \pm 0.082$ \\
\hline C22:1 (cis-13) & $1.194 \pm 0.011$ & $0.819 \pm 0.084$ & $0.487 \pm 0.117$ & $0.315 \pm 0.082$ \\
\hline C24: 1 (cis-15) & $2.192 \pm 1.567$ & $1.389 \pm 0.982$ & $0.931 \pm 0.785$ & $0.458 \pm 0.388$ \\
\hline$\sum X$ & $\mathbf{3 3 . 3 6 6}$ & $\mathbf{2 6 . 2 8 8}$ & $\mathbf{1 8 . 9 2 9}$ & $\mathbf{1 3 . 8 9 6}$ \\
Mean \pm SD & $\mathbf{3 . 3 3 7} \pm 4.427$ & $\mathbf{2 . 9 2} \pm 3.837$ & $\mathbf{2 . 7 0 4} \pm 3.223$ & $\mathbf{1 . 9 9} \pm 2.55$ \\
\hline
\end{tabular}

\begin{tabular}{|l|l|l|l|l|}
\hline Fatty acids, PUFA (\%) & Clarias gariepinus & Tilapia & Mormyrops deliciosus & Synodontis budgetti \\
\hline C18:2 (cis-9,13) & $4.173 \pm 0.063$ & $3.158 \pm 0.040$ & $2.228 \pm 0.074$ & $1.352 \pm 0.127$ \\
\hline C18:2 (trans-9,12) & $0.002 \pm 0.002$ & ND & ND & ND \\
\hline C18:3 (cis- $-9,9,12)$ & $0.005 \pm .0 .005$ & ND & ND & ND \\
\hline C18:3 (cis 9,12,15) & $0.004 \pm 0.005$ & ND & ND & ND \\
\hline C20:2 (cis-11,14) & $2.949 \pm 2.084$ & ND & ND & ND \\
\hline C20:3 (cis-8,11,14) & $0.015 \pm 0.021$ & $0.004 \pm 0.004$ & ND & ND \\
\hline C20:3 (cis-11,14,17) & $0.002 \pm 0.003$ & $0.008 \pm 0.004$ & $0.003 \pm 0.001$ & $0.001 \pm 0.004$ \\
\hline C20:4 (cis-5,8,11,14) & $8.585 \pm 0.094$ & $6.308 \pm 0.101$ & $4.222 \pm 0.176$ & $2.531 \pm 0168$ \\
\hline C22:2 (cis-13,16) & $0.027 \pm 0.038$ & ND & ND & $0.002 \pm 0.002$ \\
\hline C20:5 (cis-5,8,11,14,17) & $6.301 \pm 0.515$ & $5.018 \pm 0.495$ & $4.159 \pm 0.159$ & $2.381 \pm 0.126$ \\
\hline C22:6 (cis-4,7,10,13,16,19) & $13.645 \pm 0.288$ & $11.354 \pm 0.047$ & $9.212 \pm 0.081$ & $6.405 \pm 0.855$ \\
\hline$\sum X$ & $\mathbf{3 5 . 7 0 8}$ & $\mathbf{2 5 . 8 5}$ & $\mathbf{1 9 . 8 2 4}$ & $\mathbf{1 2 . 6 7 2}$ \\
Mean \pm SD & $\mathbf{3 . 2 4 6} \pm 4.580$ & $\mathbf{4 . 3 0 8} \pm 4.301$ & $\mathbf{3 . 9 6 5} \pm 3.404$ & $\mathbf{2 . 1 1 2} \pm 2.373$ \\
\hline
\end{tabular}

SFA, MUF, PUFA, saturated fatty acid, monounsaturated fatty acid and polyunsaturated fatty acid respectively 
Comparative Study of Some Lipid Contents of Selected Fishes In Bayelsa State, Nigeria.

Table 3. Fatty acids profile of freshwater fish species in Swali River

\begin{tabular}{|l|l|l|l|l|}
\hline Fatty acids, SFA (\%) & Clarias gariepinus & Tilapia & Mormyrops deliciosus & Synodontis budgetti \\
\hline C12:0 & $2.699 \pm 0.054$ & $1.808 \pm 0.134$ & $1.718 \pm 0.086$ & $1.723 \pm 0.295$ \\
\hline C14:0 & $0.008 \pm 0.001$ & ND & $0.001 \pm 0.001$ & ND \\
\hline C16:0 & $6.652 \pm 0.465$ & $4.421 \pm 0.444$ & $4.555 \pm 0.535$ & $4.141 \pm 0.477$ \\
\hline C18:0 & $0.022 \pm 0.002$ & $0.013 \pm 0.001$ & $0.014 \pm 0.004$ & $0.014 \pm 0.001$ \\
\hline C20:0 & $0.065 \pm 0.010$ & $0.042 \pm 0.008$ & $0.034 \pm 0.005$ & $0.022 \pm 0.009$ \\
\hline C22:0 & $0.198 \pm 0.056$ & $0.093 \pm 0.021$ & $0.020 \pm 0.008$ & $0.020 \pm 0.008$ \\
\hline C24:0 & $5.490 \pm 0.080$ & $3.822 \pm 0.094$ & $4.180 \pm 0.099$ & $2.529 \pm 0.272$ \\
\hline$\sum X$ & $\mathbf{1 5 . 1 3 4}$ & $\mathbf{1 0 . 1 9 9}$ & $\mathbf{1 0 . 5 2 2}$ & $\mathbf{8 . 4 4 9}$ \\
Mean \pm SD & $\mathbf{2 . 1 6 2} \pm 2.858$ & $\mathbf{1 . 6 7 0} \pm 2.005$ & $\mathbf{1 . 5 0 3} \pm 2.056$ & $\mathbf{1 . 4 0 8} \pm 1.710$ \\
\hline
\end{tabular}

\begin{tabular}{|l|l|l|l|l|}
\hline Fatty acids, MUFA (\%) & Clarias gariepinus & Tilapia & Mormyrops deliciosus & Synodontis budgetti \\
\hline C14:1 (cis-9) & $24.459 \pm 0.091$ & $21.158 \pm 1.385$ & $19.494 \pm 0.647$ & $17.132 \pm 0.135$ \\
\hline C16:1 (cis-9) & $8.346 \pm 0.106$ & $5.331 \pm 1.059$ & $4.348 \pm 0.723$ & $4.045 \pm 0.592$ \\
\hline C18:1 (trans-6) & $14.012 \pm 0.032$ & $12.585 \pm 0.322$ & $10.465 \pm 0.189$ & $9.062 \pm 0.282$ \\
\hline C18:1 (cis-6) & $0.002 \pm 0.001$ & $0.002 \pm 0.001$ & $0.002 \pm 0.001$ & $0.002 \pm 0.001$ \\
\hline C18:1 (trans-9) & $7.131 \pm 0.353$ & $5.423 \pm 0.349$ & $4.428 \pm 0.481$ & $3.464 \pm 0.392$ \\
\hline C18:1 (cis-9) & $0.033 \pm 0.003$ & $0.025 \pm 0.004$ & $0.020 \pm 0.008$ & $0.023 \pm 0.005$ \\
\hline C18:1 (trans-11) & $3.532 \pm 0.057$ & $2.394 \pm 0.083$ & $2.108 \pm 0.081$ & $1.914 \pm 0.073$ \\
\hline C20:1 (cis-11) & $0.053 \pm 0.005$ & $0.030 \pm 0.008$ & $0.020 \pm 0.008$ & $0.020 \pm 0.008$ \\
\hline C22:1 (cis-13) & $0.035 \pm 0.003$ & $0.021 \pm 0.008$ & $0.017 \pm 0.005$ & $0.017 \pm 0.009$ \\
\hline C24:1 (cis-15) & $13.379 \pm 0.267$ & $11.258 \pm 0.116$ & $9.327 \pm 0.095$ & $7.142 \pm 0.135$ \\
\hline$\sum X$ & $\mathbf{7 0 . 9 8 2}$ & $\mathbf{5 8 . 2 2 7}$ & $\mathbf{5 0 . 2 2 9}$ & $\mathbf{4 2 . 8 2 1}$ \\
Mean \pm SD & $\mathbf{7 . 0 9 8} \pm 8.183$ & $\mathbf{5 . 8 2 3} \pm 7.128$ & $\mathbf{5 . 0 2 3} \pm 6.387$ & $\mathbf{4 . 2 8 2} \pm 5.531$ \\
\hline
\end{tabular}

\begin{tabular}{|l|l|l|l|l|}
\hline Fatty acids, PUFA (\%) & Clarias gariepinus & Tilapia & Mormyrops deliciosus & Synodontis budgetti \\
\hline C18:2 (cis-9,13) & $0.025 \pm 0.002$ & $0.010 \pm 0.007$ & $0.021 \pm 0.007$ & $0.021 \pm 0.008$ \\
\hline C18:2 (trans-9,12) & $0.060 \pm 0.005$ & $0.045 \pm 0.005$ & $0.168 \pm 0.179$ & $0.028 \pm 0.005$ \\
\hline C18:3 (cis- 6,9,12) & $3.405 \pm 0.066$ & $2.412 \pm 0.032$ & $1.805 \pm 0.132$ & $1.647 \pm 0.054$ \\
\hline C18:3 (cis 9,12,15) & $0.007 \pm 0.001$ & $0.003 \pm 0.002$ & $0.002 \pm 0.002$ & $0.003 \pm 0.001$ \\
\hline C20:2 (cis-11,14) & $0.053 \pm 0.005$ & $0.040 \pm 0.008$ & $0.030 \pm 0.008$ & $0.020 \pm 0.008$ \\
\hline C20:3 (cis-8,11,14) & $1.105 \pm 0.038$ & $0.559 \pm 0.321$ & $0.690 \pm 0.129$ & $0.604 \pm 0.122$ \\
\hline C20:3 (cis-11,14,17) & $8.764 \pm 0.018$ & $6.756 \pm 0.027$ & $5.431 \pm 0.145$ & $4.432 \pm 0.130$ \\
\hline C20:4 (cis-5,8,11,14) & $0.099 \pm 0.026$ & $0.020 \pm 0.008$ & $0.002 \pm 0.001$ & $0.002 \pm 0.001$ \\
\hline C22:2 (cis-13,16) & $0.006 \pm 0.001$ & $0.005 \pm 0.001$ & $0.004 \pm 0.001$ & $0.002 \pm 0.001$ \\
\hline C20:5 (cis-5,8,11,14,17) & $0.006 \pm 0.001$ & $0.004 \pm 0.001$ & $0.003 \pm 0.001$ & $0.002 \pm 0.001$ \\
\hline C22:6 (cis-4,7,10,13,16,19) & $0.078 \pm 0.010$ & $0.057 \pm 0.017$ & $0.043 \pm 0.017$ & $0.033 \pm 0.012$ \\
\hline$\sum X$ & $\mathbf{1 4 . 3 1}$ & $\mathbf{9 . 9 1 1}$ & $\mathbf{7 . 1 9 9}$ & $\mathbf{6 . 7 9 4}$ \\
Mean \pm SD & $\mathbf{1 . 3 0 1} \pm 2.676$ & $\mathbf{0 . 9 0 1} \pm 2.070$ & $\mathbf{0 . 6 5 5} \pm 1.611$ & $\mathbf{0 . 6 1 8} \pm 1.361$ \\
\hline
\end{tabular}

SFA, MUF, PUFA, saturated fatty acid, monounsaturated fatty acid and polyunsaturated fatty acid respectively.

Table 4. Fatty acids profile of freshwater fish species from Tombia River

\begin{tabular}{|l|l|l|l|l|}
\hline Fatty acids, SFA (\%) & Clarias gariepinus & Tilapia & Mormyrops deliciosus & Synodontis budgetti \\
\hline C12:0 & $0.045 \pm 0.022$ & $0.031 \pm 0.021$ & $0.015 \pm 0.017$ & $0.023 \pm 0.016$ \\
\hline C14:0 & $2.476 \pm 0.112$ & $1.508 \pm 0.352$ & $0.053 \pm 0.057$ & $2.212 \pm 0.009$ \\
\hline C16:0 & $26.127 \pm 0.081$ & $24.020 \pm 0.006$ & $0.002 \pm 0.002$ & $22.012 \pm 0.006$ \\
\hline C18:0 & $7.758 \pm 0.074$ & $7.480 \pm 0.119$ & $0.038 \pm 0.041$ & $7.527 \pm 0.017$ \\
\hline C20:0 & $0.021 \pm 0.029$ & $0.017 \pm 0.024$ & $0.018 \pm 0.019$ & $0.015 \pm 0.018$ \\
\hline C22:0 & $6.102 \pm 4.313$ & $6.554 \pm 4.595$ & $4.311 \pm 4.573$ & $6.511 \pm 4.576$ \\
\hline C24:0 & $0.814 \pm 0.570$ & $0.817 \pm 0.576$ & $0.530 \pm 0.562$ & $0.795 \pm 0.559$ \\
\hline$\sum X$ & $\mathbf{4 3 . 3 4 3}$ & $\mathbf{4 0 . 4 2 7}$ & $\mathbf{4 . 9 6 7}$ & $\mathbf{3 9 . 0 9 5}$ \\
Mean \pm SD & $\mathbf{6 . 1 9 2} \pm 9.296$ & $\mathbf{5 . 7 7 5} \pm 8.615$ & $\mathbf{0 . 7 1 0} \pm 1.599$ & $\mathbf{5 . 5 8 5} \pm 7.861$ \\
\hline
\end{tabular}

\begin{tabular}{|l|l|l|l|l|}
\hline Fatty acids, MUFA (\%) & Clarias gariepinus & Tilapia & Mormyrops deliciosus & Synodontis budgetti \\
\hline C14:1 (cis-9) & $0.040 \pm 0.038$ & $0.020 \pm 0.011$ & $0.009 \pm 0.011$ & $0.021 \pm 0.014$ \\
\hline C16:1 (cis-9) & $6.649 \pm 0.419$ & $6.230 \pm 0.121$ & $0.010 \pm 0.011$ & $5.020 \pm 0.004$ \\
\hline C18:1 (trans-6) & $2.601 \pm 1.824$ & $2.345 \pm 1.644$ & $1.558 \pm 1.654$ & $2.345 \pm 1.645$ \\
\hline C18:1 (cis-6) & $13.623 \pm 0.127$ & $12.967 \pm 0.515$ & $0.019 \pm 0.021$ & $10.538 \pm 0.044$ \\
\hline C18:1 (trans-9) & $2.324 \pm 1.642$ & $2.267 \pm 1.603$ & $1.464 \pm 1.553$ & $2.233 \pm 1.578$ \\
\hline C18:1 (cis-9) & $6.679 \pm 0.436$ & $6.430 \pm 0.062$ & $0.036 \pm 0.041$ & $5.059 \pm 0.046$ \\
\hline C18:1 (trans-11) & $2.710 \pm 1.890$ & $2.679 \pm 1.879$ & $1.356 \pm 1.438$ & $2.062 \pm 1.449$ \\
\hline C20:1 (cis-11) & $3.193 \pm 0.023$ & $2.226 \pm 0.054$ & $0.013 \pm 0.014$ & $1.788 \pm 0.009$ \\
\hline C22:1 (cis-13) & $1.183 \pm 0.077$ & $1.167 \pm 0.076$ & $0.068 \pm 0.073$ & $1.163 \pm 0.073$ \\
\hline C24:1 (cis-15) & $0.812 \pm 0.569$ & $0.809 \pm 0.570$ & $0.498 \pm 0.529$ & $0.757 \pm 0.532$ \\
\hline$\sum X$ & $\mathbf{3 9 . 8 1 4}$ & $\mathbf{3 7 . 1 4}$ & $\mathbf{5 . 0 3 1}$ & $\mathbf{3 0 . 9 8 6}$ \\
Mean \pm SD & $\mathbf{3 . 9 8 1} \pm \mathbf{4 . 4 . 0 5 0}$ & $\mathbf{3 . 7 1 4} \pm 3.875$ & $\mathbf{0 . 5 0 3} \pm 0.678$ & $\mathbf{3 . 0 9 9} \pm 3.086$ \\
\hline
\end{tabular}


Comparative Study of Some Lipid Contents of Selected Fishes In Bayelsa State, Nigeria.

\begin{tabular}{|l|l|l|l|l|}
\hline Fatty acids, PUFA (\%) & Clarias gariepinus & Tilapia & Mormyrops deliciosus & Synodontis budgetti \\
\hline C18:2 (cis-9,13) & $4.603 \pm 0.083$ & $4.417 \pm 0.082$ & $0.076 \pm 0.081$ & $4.372 \pm 0.086$ \\
\hline C18:2 (trans-9,12) & $3.007 \pm 2.108$ & $2.920 \pm 2.051$ & $1.898 \pm 2.013$ & $2.860 \pm 2.012$ \\
\hline C18:3 (cis- 6,9,12) & $0.030 \pm 0.032$ & $0.019 \pm 0.022$ & $0.019 \pm 0.020$ & $0.015 \pm 0.018$ \\
\hline C18:3 (cis 9,12,15) & $0.022 \pm 0.026$ & $0.019 \pm 0.023$ & $0.018 \pm 0.019$ & $0.015 \pm 0.018$ \\
\hline C20:2 (cis-11,14) & $0.006 \pm 0.002$ & $0.004 \pm 0.002$ & $0.001 \pm 0.001$ & $0.002 \pm 0.001$ \\
\hline C20:3 (cis-8,11,14) & $0.098 \pm 0.012$ & $0.048 \pm 0.046$ & $0.023 \pm 0.025$ & $0.066 \pm 0.034$ \\
\hline C20:3 (cis-11,14,17) & $4.358 \pm 3.055$ & $4.377 \pm 3.075$ & $2.213 \pm 2.348$ & $3.347 \pm 2.353$ \\
\hline C20:4 (cis-5,8,11,14) & $8.438 \pm 0.025$ & $8.335 \pm 0.236$ & $0.067 \pm 0.073$ & $7.565 \pm 0.056$ \\
\hline C22:2 (cis-13,16) & $6.412 \pm 4.450$ & $6.373 \pm 4.429$ & $3.753 \pm 3.980$ & $5.713 \pm 3.961$ \\
\hline C20:5 (cis-5,8,11,14,17) & $5.230 \pm 0.052$ & $5.203 \pm 0.052$ & $0.051 \pm 0.054$ & $4.213 \pm 0.042$ \\
\hline C22:6 (cis-4,7,10,13,16,19) & $13.644 \pm 0.103$ & $13.538 \pm 0.063$ & $0.011 \pm 0.012$ & $12.234 \pm 0.028$ \\
\hline$\sum X$ & $\mathbf{4 5 . 8 4 8}$ & $\mathbf{4 5 . 2 5 3}$ & $\mathbf{9 . 1 3}$ & $\mathbf{4 0 . 4 0 2}$ \\
Mean \pm SD & $\mathbf{4 . 1 6 8} \pm 4.289$ & $\mathbf{4 . 1 1 4} \pm 4.260$ & $\mathbf{0 . 8 3} \pm 1.27$ & $\mathbf{3 . 6 7 3} \pm 3.839$ \\
\hline
\end{tabular}

SFA, MUF, PUFA, saturated fatty acid, monounsaturated fatty acid and polyunsaturated fatty acid respectively

Table 5: Fatty Acid Ratio of Fish Samples from Lagos and Selected Rivers in Bayelsa State Nigeria

\begin{tabular}{|c|c|c|c|c|c|}
\hline Rivers & Fatty acid ratios & $\begin{array}{l}\text { Clarias } \\
\text { gariepinus }\end{array}$ & $\begin{array}{l}\text { Oreochromis } \\
\text { niloticus }\end{array}$ & $\begin{array}{l}\text { Mormyrops } \\
\text { deliciosus }\end{array}$ & $\begin{array}{l}\text { Synodontis } \\
\text { budgetti }\end{array}$ \\
\hline \multirow[t]{7}{*}{ Lagos } & n6/n3 & 0.427 & 0.402 & 0.388 & 0.335 \\
\hline & PUFA/SFA & 0.902 & 0.938 & 0.992 & 0.773 \\
\hline & LA/ALA & 0.500 & 0 & 0.50 & 0 \\
\hline & n-6 \% PUFA & 29.841 & 28.634 & 27.886 & 25.067 \\
\hline & $\mathrm{n}-3 \%$ PUFA & 69.943 & 70.864 & 71.976 & 74.831 \\
\hline & EPA \% PUFA & 18.473 & 18.699 & 17.147 & 19.470 \\
\hline & DHA \% PUFA & 51.461 & 52.443 & 54.812 & 55.193 \\
\hline \multirow[t]{7}{*}{ Amassoma } & $\mathrm{n} 6 / \mathrm{n} 3$ & 0.431 & 0.385 & 0.316 & 0.259 \\
\hline & PUFA/SFA & 0.895 & 0.772 & 0.665 & 0.489 \\
\hline & LA/ALA & 0.500 & 0 & 0 & 0 \\
\hline & n-6 \% PUFA & 24.056 & 24.402 & 21.297 & 19.973 \\
\hline & n-3 \% PUFA & 55.87 & 63.335 & 67.449 & 77.225 \\
\hline & EPA\% PUFA & 17.646 & 19.412 & 20.948 & 18.790 \\
\hline & DHA \% PUFA & 38.213 & 43.923 & 46.399 & 50.545 \\
\hline \multirow[t]{7}{*}{ Swalli } & $\mathrm{n} 6 / \mathrm{n} 3$ & 1.085 & 0.313 & 0.043 & 0.053 \\
\hline & PUFA/SFA & 0.946 & 0.072 & 0.684 & 0.804 \\
\hline & LA/ALA & $8.571 * *$ & $15^{*}$ & $84 *$ & $9.333 * *$ \\
\hline & n-6 \% PUFA & 0.692 & 0.201 & 0.028 & 0.029 \\
\hline & n-3 \% PUFA & 0.636 & 0.646 & 0.653 & 0.559 \\
\hline & EPA \% PUFA & 4.193 & 4.036 & 4.167 & 2.944 \\
\hline & DHA \% PUFA & 54.507 & 57.512 & 59.731 & 48.572 \\
\hline \multirow[t]{7}{*}{ Tombia } & n6/n3 & 0.447 & 0.444 & 0.837 & 0.459 \\
\hline & PUFA/SFA & 1.058 & 1.119 & 1.838 & 1.034 \\
\hline & LA/ALA & $136.682 *$ & $135.684 *$ & $105.444 *$ & $190.667 *$ \\
\hline & n-6 \% PUFA & 18.408 & 18.419 & 0.734 & 18.719 \\
\hline & n-3\% PUFA & 41.214 & 41.456 & 0.876 & 40.746 \\
\hline & EPA \% PUFA & 11.407 & 0.012 & 0.559 & 10.428 \\
\hline & DHA \% PUFA & 29.759 & 29.916 & 0.121 & 30.281 \\
\hline
\end{tabular}

$n-3=$ Omega 3-fatty acid, $n-6=$ Omega 6-fatty acid, PUFA = Poltunsaturated Fatty Acid, SFA

= Saturated Fatty Acid, LA= Linoleic acid, ALA= Linolenic acid. Linoleic acid/Linolenic acid ratio was calculated using the C18:2(9,12) vs C18:3(9,12,15). All C18:2(9,12) are present in trans form; *, values > 10; while **, values $<10$ and represents the best results.

Table 6: Cholesterol, HDL, and LDL content of Fresh Water Fish Species from Bayelsa and Lagos Areas of Nigeria (mg/100g DW basis).

\begin{tabular}{|l|l|l|l|l|}
\hline Fish Species & LR & AR & SR & TR \\
\hline C. gariepinus & & & & \\
\hline$*$ & $5.777 \pm 0.091$ & $5.544 \pm 0.026$ & $5.530 \pm 0.022$ & $5.224 \pm 0.022$ \\
\hline$* *$ & $0.522 \pm 0.002^{\mathrm{ab}}$ & $0.511 \pm 0.003^{\mathrm{c}}$ & $0.500 \pm 0.001^{\mathrm{a}}$ & $0.493 \pm 0.006^{\mathrm{b}}$ \\
\hline$* * *$ & $0.150 \pm 0.002$ & $0.140 \pm 0.002$ & $0.140 \pm 0.002$ & $0.123 \pm 0.006$ \\
\hline O. niloticus & & & & \\
\hline$* *$ & $5.677 \pm 0.097^{\mathrm{abc}}$ & $5.440 \pm 0.020^{\mathrm{a}}$ & $5.190 \pm 0.020^{\mathrm{b}}$ & $5.140 \pm 0.020^{\mathrm{c}}$ \\
\hline$* * *$ & $0.448 \pm 0.065^{\mathrm{abc}}$ & $0.410 \pm 0.006^{\mathrm{a}}$ & $0.400 \pm 0.000^{\mathrm{b}}$ & $0.370 \pm 0.030^{\mathrm{c}}$ \\
\hline S. budgetti & $0.144 \pm 0.007$ & $0.130 \pm 0.000$ & $0.130 \pm 0.000$ & $0.113 \pm 0.006$ \\
\hline$*$ & & & & \\
\hline$* *$ & $5.668 \pm 0.17^{\mathrm{abc}}$ & $5.340 \pm 0.020^{\mathrm{a}}$ & $5.170 \pm 0.02^{\mathrm{b}}$ & $5.120 \pm 0.020 \mathrm{c}$ \\
\hline$* * *$ & $0.387 \pm 0.012^{\mathrm{ab}}$ & $0.310 \pm 0.000^{\mathrm{c}}$ & $0.300 \pm 0.000^{\mathrm{a}}$ & $0.270 \pm 0.030^{\mathrm{b}}$ \\
\hline M. deliciosus & $0.133 \pm 0.006^{\mathrm{abc}}$ & $0.120 \pm 0.000^{\mathrm{a}}$ & $0.120 \pm 0.000^{\mathrm{b}}$ & $0.103 \pm 0.006^{\mathrm{c}}$ \\
\hline$*$ & & & & \\
\hline$* *$ & $5.543 \pm 0.020$ & $5.273 \pm 0.042$ & $5.150 \pm 0.020$ & $5.100 \pm 0.020$ \\
\hline$* * *$ & $0.367 \pm 0.007^{\mathrm{abc}}$ & $0.210 \pm 0.000^{\mathrm{a}}$ & $0.200 \pm 0.000^{\mathrm{b}}$ & $0.170 \pm 0.030^{\mathrm{c}}$ \\
\hline
\end{tabular}

*cholesterol, $* * H D L$ (High density lipoprotein), ${ }^{* * *}$ LDL (Low density lipoprotein). LA, Lagos river (Ikorodu 
areas); AR, Amassoma river; SR, Swali river; and TR, Tombia river (in Bayelsa State). Values with the same superscript on the horizontal line are significant at $p<0.05$.

\section{References}

[1] K.C Justi, C. Hayashi, J.V. Visentainer, N.E. de Souza, and M. Matsushita, The influence of feed supply time on the fatty acid profile of Nile tilapia (Oreochomis niloticus) fed on a diet enriched with n-3 fatty acids, Food Chemistry, 80, 2003, 489- $\quad 493$

[2] C.A. Burtis, E.R. Ashwood, and D.E. Bruns, Tietz. Fundamentals of clinical chemistry (Philadelphia, Saunders, 2012).

[3] W.C Bowman, and M.J Rand, Texbook of Pharmacology (Oxford, Blackwell, 1980).

[4] M.H. Moghadasian, Advances in Dietary Enrichment with n-3 Fatty Acids, Reviews in Food Science and Nutrition 48 (5), 2008, 402-10.

[5] L. Cleland, M. James, and S. Proudman, Fish oil: What the prescriber needs to know, Arthritis Research \&Therapy 8 (1), 2006, 679-81.

[6] W.E Conner, The beneficial effects of omega-3 fatty: cardiovascular diseases and neurodevelopment, Currrent Opinion in Lipidology, 8, 1997, 1-3.

[7] P. Hickley, R.C. Balley, D.M. Haper, R. Kundu, S.M. Muchiri, R. North, and A. Taylor, The status and future of the Lake Naivasha fishery, Keny, Hydrobiol., 2003, 488-492.

[8] M. Tapas, and G. Santinath, Lipid profile and fatty acid composition in Eggs of common carp (Cyprinus carpio), J. of Oleo Science, 52 (8), 2003, 439-442.

[9] Food and Agricultural Organization (FAO), Artificial Reproduction and Pond Rearing of the African Catfish Claria gariepinus, Fisheries and aquaculture Department, 33, 1999, FAO Rome.

[10] Federal Department of Fisheries $(F D F)$, (Abuja Nigeria, Fisheries Statistics of Nigeria, 2004)

[11] FAO, The State of World Fisheries and Aquaculture, FAO Fisheries and Aquaculture Department Food and Agriculture Organization of the UN, Rome, 2009.

[12] W. Horwitz, Official Methods of Analysis of the Association of Official Analytical Chemists (AOAC), (Washington DC, 2006).

[13] R.G. Ackman, Seafood lipid and fatty acids, Food Rev. Int. 6(4), 1990, 617-646.

[14] R.G. Ackman, Nutritional composition of fats in sea foods, Prog. Food Safety Nutr. Sci., 1989, 161-241.

[15] Y. Ito, and K. Watanabe, Variation in chemical composition of fillet of corvine and 'pescada-foguete', Contr. Inst. Oceanogr. Univ. Sao Paolo (Ser. Technol.), 5, 1968, 1-6.

[16] N. Bouriga, S. Selmi, E. Faure, E. Trabelsi, Biochemical composition of three Tunisian Silverside (fish) populations caught in open sea, lagoon and Island coasts, Afri. J. Biotechnol., 9, 2010, 4114-4119.

[17] H.K. Mangold, K.D. Mukherjee, New methods of quantization in thin-layer chromatography: Tubular thin-layer chromatography (TTLC). J. Chromatogr. Sci., 13 (9), 1975, 398-402.

[18] J.H. All-Jedah, M.Z. Ali, R.K. Robinson, The nutritional importance to local communities of fish of the coast of Qatar. Nutr. Food Sci. 6, 1999, 288-294.

[19] A.K. Jitender Kumar Jakhar, A. Pal, N.P. Devivaraprassad Reddy, G. Sahu, H.K. Venkateshwarlu, and P. Verdia, Fatty acid composition of some selected Indian Fishes, Afr. J. of Basic \& Applied Sci., 4(5), 2012, 155-160.

[20] S. Dikel, Comparative analysis of carcass composition and nutritive contents of rainbow trouts (Oncorhyncus mykiss) were produced in fresh and sea water, Symposium of $10^{\text {th }}$ National Sea Products, Adana / Turkey, 1999, 97-1111.

[21] E. Mendez, M. Fermandez, G. Pazo, and M.A. Grompone, Hake roe lipid: Composition and changes following cooking. Food Chemistry, 45, 1992, 179-181.

[22] K.I. Jeyasanta, and J. Patterson, Total lipid, phospholipid and cholesterol content of Tuticorin, South east caost of India. Sky J. of Food Sci., vol. 2(6), 2013, 47-53.

[23] N.B. Javitt, Bile acid synthesis from cholesterol regulatory and auxiliary pathway, FASEB J., 8(15), 199 4, 1308-11.

[24] F.C. Kupper, L.J. Carpenter, G.B. McFiggans, C.J. Palmer, T.J. Waite, E.M. Boneberg, S. Woitsch, M. Weiller, R. Abela, D. Grolimund, P. Potin, A. Butler, G.W. Luther, P.M.H. Kroneck, J.M. Meyer-Lecerf, and M. de Lorgeril, Dietary Cholesterol: from physiology to cardiovascular risk, Br. J. Nutr., 106 (1), 2011, 6-14.

[25] FAO, Fats and fatty acids in human nutrition, in FAO food and nutrition paper 91(Ed), Report of an expert consultation 10-14 November 2008, Geneva (Rome, Food and Agricultural Organization of United Nations, 2010) 90-106.

[26] D. Kumar, N.A. Khan, M.A. Rahman, and F. Ahamed, Biochemical Composition of Some Small Indigenous Freshwater Fishes from the River Mouri, Khulna, Bangladesh, Pak. J. Biol. S CI., 10 (9), 2007, 1559-1556.

[27] W. Steffens, Freshwater fish- wholesome foodstuffs. Bulgarian, J. Agric. Sci., 12, 2006, 320-328.

[28] C.H. Ugoala, G.I. Ndukwe, and T.O. Audu, Investigation of the constituent fatty acids of some freshwater fishes common in Nigeria, Braz. J. Aquat. Technol., 13(1), 2009, 65-70.

[29] A.D. Andrade, A.F. Rubira, M. Matsushira, and N.E. Souza, N-3 Fatty acids in freshwater fish from South Brazil, Journal of the American Oil Chemist Society, 72, 1995, 1207-1210.

[30] R.G. Ackman, and R.F. Takeuchi, Composition of FAand lipids of smolting hatchery fed on wild Atlantic salmon (salmo salar), Lipids, 21, 1986, 117-9.

[31] R.C. Tilton, A. Balows, D.C. Hohnadel, and R.F. Reiss, Clinical Laboratory Medicine (Missouri USA, Mosby Year Book, 1992). 